\title{
Don't let up: implementing and sustaining change in a new post-licensure education model for developing extended role practitioners involved in arthritis care
}

\author{
This article was published in the following Dove Press journal: \\ Journal of Multidisciplinary Healthcare \\ 26 August 2015 \\ Number of times this article has been viewed
}

\author{
Katie Lundon ${ }^{1,3}$ \\ Rachel Shupak ${ }^{1-3}$ \\ Sonya Canzian ${ }^{4}$ \\ Ed Ziesmann ${ }^{5}$ \\ Rayfel Schneider 6,7 \\ 'Office of Continuing Professional \\ Development, Faculty of Medicine, \\ University of Toronto, ${ }^{2}$ Division of \\ Rheumatology, St Michael's Hospital, \\ ${ }^{3}$ Department of Medicine, University \\ of Toronto, ${ }^{4}$ Trauma/Neurosurgery \\ and Mobility Programs, St Michael's \\ Hospital, ${ }^{5}$ Programs and Services, \\ The Arthritis Society, ${ }^{6}$ Division of \\ Rheumatology, The Hospital for Sick \\ Children, ${ }^{7}$ Department of Paediatrics, \\ University of Toronto, Toronto, ON, \\ Canada
}

Key message: Across a 9-year period, the Advanced Clinician Practitioner in Arthritis Care program has achieved a set of short-term "wins" giving direction and momentum to the development of new roles for health care practitioners providing arthritis care.

Implications: This is a viable model for post-licensure training offered to multiple allied health professionals to support the development of competent extended role practitioners (extended scope practice). Challenges at this critical juncture include: retain focus, drive, and commitment; develop academic and financial partnerships transferring short-term success to long-term sustainability; advanced, context-driven, system-level evaluation including fiscal outcome; health care policy adaptation to new human health resource development.

Supporting evidence: Success includes: completed 2-year health services research evaluating 37 graduates; leadership, innovation, educational excellence, and human health resource benefit awards; influential publications/presentations addressing post-licensure education/outcome, interprofessional collaboration, and improved patient care.

Keywords: human health resource development, post-licensure education, arthritis, extended role practitioners, allied health professionals

\section{Introduction}

After the first set of short-term wins, a change effort will have direction and momentum. In successful situations, people build on this momentum to make a vision a reality by keeping urgency up and a feeling of false pride down; by eliminating unnecessary, exhausting, and demoralizing work; and by not declaring victory prematurely.

- Cohen DS. ${ }^{1}$

\section{Background}

The Advanced Clinician Practitioner in Arthritis Care (ACPAC) program is a unique, interprofessional, clinical, and academic training program currently offered for physical therapists, occupational therapists, and nurses experienced in the musculoskeletal (MSK) field. It is a post-licensure program offered through the Department of Continuing Professional Development, Faculty of Medicine, at The University of Toronto, Canada. ${ }^{2}$ The ACPAC program is offered principally at two main academic health care centers - St Michael's Hospital (adult) and the Hospital for Sick Children (pediatric), but additionally relies upon a broad network of health care (community and academic) institutions and involves over 90 faculty. The vision for the ACPAC program,
Correspondence: Katie Lundon Office of Continuing Professional Development, Faculty of Medicine, University of Toronto, 650-500 University Avenue, Toronto, ON M5G IV7, Canada Email katie.lundon@utoronto.ca 
including competency development, was formulated under the leadership of two academic rheumatologists (the adult and pediatric medical directors) and a physical therapist with a $\mathrm{PhD}$ in bone pathophysiology (program director) all of whom have worked collaboratively to direct and coordinate the program since its inception. ${ }^{3}$ The focus of the ACPAC program is on the assessment, diagnosis, triage, and independent but collaborative management of select MSK and arthritis-related disorders with the rationale for and processes involved in the inception, development, implementation, ${ }^{3}$ and leadership ${ }^{4}$ of the ACPAC program described fully elsewhere.

In a brief review, experienced physical therapists, occupational therapists, and nurses are prepared, through advanced academic and clinical training, for extended practice roles (Table 1) within the context of a variety of arthritis care settings. The ACPAC program consists of five intensive on-site weeks interspersed with advanced clinical training and self-directed learning opportunities offered between September and June of each academic year. The foundation of the curriculum is based on the integration of material from the rheumatology and orthopedic fields and consists of four core components: Component I - Advanced Rheumatology Theory (online); Component II - Advanced Assessment and Integrative Sessions; Component III - Advanced Clinical Training in Rheumatology (general adult and pediatric rheumatology, as well as surgical/specialty clinics); and Component IV - Health Promotion, Advocacy, and Leadership in Arthritis Care. Both program and candidate evaluation involve extensive theoretic and practical skill examinations, clinical competency appraisals based on CanMEDS, clinical case reports, portfolios, and structured learning projects as well as online advanced rheumatology learning assessments. Each ACPAC trainee must achieve at least 70\%

Table I ACPAC program-trained Extended Role Practitioner (ERP) profile

I. ACPAC program-trained ERPs have been prepared to work in settings for ongoing management and triage, two identified requirements to establish new interprofessional models of care.

2. These practitioners, who are physical therapists, occupational therapists, or nurses with expertise in the musculoskeletal field, have expanded and advanced knowledge, clinical skills, and attitudes related to arthritis care obtained through additional training and formal evaluation with measured competencies.

3. ERP roles can be autonomous or require additional performance expectations of authorized activities which are currently achieved through delegation or medical directives*

Notes: *Medical directives are defined as "indirect physician orders, used to expedite patient care by competent health professionals". ${ }^{23}$

Abbreviation: ACPAC, Advanced Clinician Practitioner in Arthritis Care. and/or "meets expectations" for each evaluation component (http://www.acpacprogram.ca). The expectations for increased clinical responsibilities in the extended practice role are fully described by Lundon et al. ${ }^{3}$

The goal is to engage this new human health care resource as integral participants in the design and delivery of innovative models of arthritis care. There are currently 47 graduates working across a spectrum of urban-academic $(n=30)$, community $(n=8)$, and remote $(n=9)$ clinical settings. These graduates are filling the gap in arthritis care to contend with 1) the need to improve an interprofessional approach to care that is regarded to optimize care of a growing population of patients living with arthritis ${ }^{5,6}$ and 2) a relatively insufficient number of traditional arthritis care specialists resulting in increasingly long wait times and poor access to care. ${ }^{7,8}$ Finally, and not insignificantly, the maximizing of scopes of practice of existing and experienced human health resource (ie, OT, PT, RN), which entails formal training processes with measured competencies to support extended practice roles, has the intuitive benefit of improving access to and efficiency of arthritis care in supportive collaborative care environments.

\section{The challenge}

Despite the recent changes in health care service provisions for numerous health professionals to broaden scope of practice in Ontario (MOHLTC 2012), ${ }^{9}$ related academic, regulatory, and professional bodies have been slow to accommodate for the training logistics required to support such change. To date, it has been left up to the individual and/or institution to drive new initiatives. Introduction of regulatory structure to broaden diversity of workforce roles in health care has lagged significantly behind the realities of practice in Ontario, a phenomenon also observed in other health care systems. ${ }^{10}$ It is under these conditions that the ACPAC program leadership has substantially increased their effort across the past few years to sustain this educational initiative. In anticipation of rapid changes in health care policy, these

Table 2 Arthritis burden

I. 4.6 million Canadians live with arthritis and MSK disorders. Arthritis and MSK conditions are a leading cause of morbidity, disability, and health care utilization.

2. 4.4 million Canadians live with OA. This will double to 9 million in the next 20 years.

3. More than 272,000 Canadians live with RA ( $0.9 \%$ of Canadian adult population) $\rightarrow$ in the next 30 years this will increase to $1.3 \%$.

4. The number of Canadians with untreated RA is expected to increase from 117,000 to 230,000 in the next 30 years.

Note: Data from Bombardier et al. ${ }^{20}$

Abbreviations: MSK, musculoskeletal; OA, osteoarthritis; RA, rheumatoid arthritis. 
efforts include overseeing both continued generation of competent Extended Role Practitioners (ERPs) and the evaluation of these roles at the health services level. We feel strongly that this is not a time to let up or let go.

\section{Early wins}

Across a 9-year period, the ACPAC program has achieved a set of short-term "wins" giving direction and momentum to the development of new models of arthritis care in Ontario.

\section{Community reach}

The longer term viability of the ACPAC program required an early and sustained effort to develop strong financial and in-kind linkages with key stakeholders including: the government (The Ministry of Health and Long-Term Care-MOHLTC); industry; academia (Faculty of Medicine, University of Toronto) and related academic health care institutions (in particular, the St Michael's Hospital and The Hospital for Sick Children); and The Arthritis Society (advocacy group).

\section{The Ministry of Health and Long-Term Care}

In terms of being recognized by and relevant to the Ministry of Health in Ontario, in 2009 the ACPAC program was selected as one of three top innovations in human health resource initiatives in Ontario.

\section{Academic health care institutions}

The success of the ACPAC program has relied upon the firm commitment of St Michael's Hospital and The Hospital for Sick Children which as large academic health care institutions have provided the necessary infrastructure including physical environment, administration support, and expert faculty resources. Administrators within these institutions recognized the urgent nature of impending demographic changes and simultaneous human health resource shortages in the area of arthritis care and as such were receptive and willing to espouse this novel program. The supportive role of core academic teaching hospitals has been critical to lead and foster the development of new human health resource which is an integral part of the design of a larger chronic disease (arthritis) management strategy. The synergistic relationship between commitment as host site and the training program itself is evident as the ACPAC program has in turn drawn local, national, and international attention to these institutions for their role in supporting innovation in post-licensure, interprofessional training opportunities.

\section{The Arthritis Society}

Graduates of the ACPAC program employed at The Arthritis Society have become integral to the advanced clinical delivery of primary health care for individuals with arthritis in diverse clinical settings throughout the province. The specialized skills acquired by these extended role practitioners have been instrumental to The Arthritis Society's increased capacity to provide advanced therapy and consultation services to Ontarians, particularly those in rural, remote, and underserviced communities. The proven effectiveness of the training program has served as an important foundation upon which The Arthritis Society can build its efforts to identify and deliver new innovative models of care that respect current health care priorities, build on existing community resources, and supports improved health care capacity, patient outcomes, and access to coordinated, interprofessional care.

\section{Strengthened interprofessional relationships}

The Canadian Rheumatology Association, a physician-based group, and the Arthritis Health Professions Association have endorsed the ACPAC program.

1. The efforts of the Arthritis Alliance of Canada and the Ontario Rheumatology Association to design and promote effective and efficient models of arthritis care are strongly reliant upon the advanced skills, knowledge, and attitudes inherent to the ACPAC program-trained ERPs.

2. A supportive review issued by the Canadian Medical Association ${ }^{11}$ following their appraisal of a presentation made at the American College of Rheumatology of the system-level impact of ACPAC-trained ERPs clearly identified that "Arthritis care in Ontario is enhanced by extended role practitioners".

\section{Education/scholarly activity}

1. The ACPAC program exemplifies leadership in interprofessional education. The success of the initiative has largely been a result of the cooperative effort of both the medical and allied health professionals who have contributed to program development, operation, and evaluation with the aim of improving patient care. A significant achievement is the growing cohort of graduate ERPs who are now represented as faculty.

2. There have been numerous publications (accepted and pending) focusing on leadership, post-licensure program design/outcome, interprofessional education and care, 
system integration and change/clinical utilization and outcome, and patient care and satisfaction.

3. The ACPAC program has been sought for both peerreviewed and invited presentations (including keynote) at local, national, and international levels on a range of topics relating to the ACPAC program including: curriculum design, leadership, human health resource development and utilization, health services evaluation, and interprofessional care.

\section{Research activity}

\section{Evaluation of program outcome}

1. Competency: pre-post theory and practical skills evaluation

An extensive pre-post data set - generated from results of theoretical and practical (OSCE) examinations - measured significant change (growth) in advanced skills and knowledge in arthritis and supports competency in these new practitioners. ${ }^{3}$ These changes in knowledge and skills are considerable as they were demonstrated in health care professionals already highly trained in arthritis care, underscoring the importance of this educational initiative.

2. Health services evaluation (2009-2011)

The early impact of ACPAC program-trained ERPs on the Ontario health care system was evaluated using the Balanced Scorecard approach of Kaplan and Norton. ${ }^{12}$ The evaluation framework was a further modified version of the Province of Ontario Hospital Report: Rehabilitation series, ${ }^{13}$ with a four quadrant approach representing four perspectives supporting translation of strategic objectives into measurable performance indicators. The four perspectives included that of patients and stakeholders, clinical utilization and outcomes, system integration and change, and financial performance and condition. ${ }^{14}$ There is evidence that, in general, ACPAC program-trained ERPs have roles which are responsive to a dynamically evolving health care environment. ${ }^{15-17}$

\section{Key implications of system-level evaluation findings for health care provision in Ontario}

Detailed results and implications based on the extensive health services evaluation ${ }^{14}$ were presented at the government-level to the Ministry of Health (Human Resources Division). Key implications of health care provision by ACPAC programtrained ERPs supported positive changes identified by improved access (especially in rural and remote regions), strengthened human health resource capacity, perceived impact on patient outcomes, and an abundance of potential opportunities for broadened role promotion and utilization.

\section{Relevance to key stakeholders: The Ministry of Health and Long-Term Care}

The optimizing of human health resource utilization and maximizing scopes of practice through development of extended role, scope, or advanced practice practitioners, particularly in the MSK field, ${ }^{18}$ is of global interest. The ACPAC program initiative is also aligned with a current mandate in Ontario to expand roles of existing human health care providers to meet health care service needs. ${ }^{9,19}$ Furthermore, it represents a robust approach to collectively train and generate competent practitioners from multiple professions with expertise in arthritis care. While changes in regulation are broadly welcomed to accommodate and support new and expanded roles, the professionals involved in extended role practice must both assure and be assured that new human health resource positions are competent, transportable, secure, and not vulnerable to politically driven changes in priority.

The ACPAC program has been a leading interprofessional educational initiative offered at the post-licensure level that has effectively generated a new type of health care worker. At this juncture, a critical opportunity exists for our academic institutions to embrace post-licensure, clinical, and academic education training programs (such as ACPAC). This will ensure standardized processes are in place to train competent health care workers essential to develop new models of care, as well as optimize the use of existing human health resources. It is clear that an opportunity exists for relevant health professionals willing to undergo additional formal training to achieve the necessary competencies to fill a system-level gap in arthritis/MSK care at a broader (national and international) level. Recent effort to broaden our reach at the national level has been made to secure the best candidates and ensure a standardized training process is accessible across the country so that care is distributed in regions of most need. In Canada, as we contend with the impending demographic statistics outlined in Table $2,{ }^{20}$ the ongoing generation of this new human health resource will be critical to the success of new models of care.

There is a renewed sense of urgency as we plan the next steps for the ACPAC program as it transitions from a human health resource initiative into a sustainable academic program. This will entail new thinking around credentialing 
and academic recognition of training programs which lead to specialized practice in non-physician health care providers which is receiving considerable attention internationally. ${ }^{21,22}$ Challenges at this critical juncture include: retaining focus, drive and commitment; developing academic partnerships where the short-term success is transferred to long-term sustainability and where there is high regard for standardized, post-licensure education programming that is competency based and evaluated on an ongoing basis at the system level.

Our challenge to "don't let up" requires continued:

1. Conveyance of the drive and commitment required in developing and training competent and adequately trained ERPs prepared to fill the gap in arthritis care within a sustainable, relevant academic home.

2. Monitoring and measuring progress on a consistent basis (in the form of ongoing, health services evaluation of ERPs in relevant clinical settings), as well as measuring fiscal impact of this new human health care resource.

It is critical that the leaders of the ACPAC program stay the course, remain focused, and demonstrate that we are not easing the pressure to achieve the vision in which so much energy has been invested. This will require sustained effort to attract new partners (academia, industry) who will strengthen the opportunities for the ACPAC program and its graduates.

\section{Conclusion}

The product of the ACPAC program (the ACPAC programtrained ERP) is aligned with the mandate of, and desired direction professed by, the Ministry of Health in Ontario as well as a key advocacy group (The Arthritis Society). The ACPAC program is a rigorous training model which aims to develop and further optimize relevant human health resources to improve arthritis care. This type of initiative aims to fulfill the education requirements that are increasingly relevant to health care regulatory bodies as their membership is challenged with rapidly changing scopes of practice which also may involve skill mixing. It is essential that partnerships are broadened, particularly in academia (credibility) and industry (fiscal), in order to achieve sustainability and maintain relevance to health care delivery. We believe that the position we are in and the processes that confront us at this time are relevant to administrators contemplating introducing new human health resource - or considering new ways of delivering care using traditional human health resources - and for whom a concern is the underling academic/clinical training necessary to fulfill these positions.
The ACPAC program has realized significant shortterm wins which have propelled the change effort forward. This has enabled stakeholders to tackle some of the bigger and deeper changes that will deliver substantial benefits, including improved patient care and access, particularly in remote areas of Ontario. At this point, it is critical that change processes continue to take root and are supported, recognizing that the ACPAC Program-trained ERPS are integral to the success and design of new models of arthritis care. We need to retain a sense of urgency - don't let up! and persist in fostering collaboration between professional bodies, health care institutions, universities, and the Ministry of Health to assure continued advancement of this leading-edge, innovative, academic/clinical-based educational program.

\section{Key Points}

- This is a viable model for interprofessional, post-licensure training that would markedly benefit management of other chronic disease streams (ie mental health, cardiovascular, neurology).

- Graduates of the ACPAC program have demonstrated competency in advanced knowledge and skills for practising as ERPs in the arthritis/musculoskeletal field. Their presence enhances the available human health resource pool for patients with arthritis.

- The ACPAC program represents a significant innovation in academic and clinical post-licensure education for allied health professionals.

- In order to achieve sustainable change in healthcare system renewal, stakeholders need to be open to integrating interprofessional care, including new role development, into existing strategies.

- Interprofessional healthcare models which incorporate health professionals with broadened scopes of practice will need to evolve given demographic and chronic disease trends.

- A shift in traditional roles and professional boundaries by well-trained and competent new healthcare providers (ie ERPs) can narrow the gaps in healthcare to allow patients to receive the right care, at the right time, by the right person making continued development of these roles well worth the effort to overcome the challenges.

\section{Lessons Learned}

1. Formal interprofessional training opportunities and rigorous evaluation measures established at the post-licensure level supports healthcare professionals from multiple professions and disciplines who are experienced in 
arthritis care to further develop as extended role (scope) practitioners within this field.

2. The development of new human health resource which is multidisciplinary in nature requires steadfast interprofessional leadership and buy-in from multiple stakeholders.

3. Changes at the system level to better accommodate interprofessional collaboration begin with interprofessional education opportunities such as the ACPAC Program initiative.

\section{Acknowledgment}

The foundation for this manuscript is based on ideas presented in The Heart of Change Field Guide: Tools and Tactics for Leading Change in Your Organization - Harvard Business Press. ${ }^{1}$

\section{Disclosure}

The authors have no conflicts of interest in this work.

\section{References}

1. Cohen DS. Heart of Change Field Guide. Tools and Tactics for Leading Change in Your Organization. Part III: Implementing and Sustaining the Change. Step 7. Don't Let Up. Deloitte Development LLC, USA: Harvard Business Press; 2005:163.

2. Advanced Clinician Practitioner in Arthritis Care (ACPAC). University of Toronto. Available from: http://www.acpacprogram.ca. Accessed: June $15,2015$.

3. Lundon K, Shupak R, Schneider R, Herold Mcllroy J. Development and early evaluation of an inter-professional post-licensure education programme for extended practice roles in arthritis care. Physiotherapy Canada. 2011;63(1):94-103.

4. Lundon K, Shupak R, Sunstrum-Mann L, Galet D, Schneider R. Leading change in the transformation of arthritis care through development of an interprofessional academic clinical education training model. Healthcare Quarterly. 2008;11(3):59-65.

5. MacKay C, Devitt R, Soever L, Badley E. An exploration of comprehensive interdisciplinary models for arthritis. In: Arthritis Community Research and Evaluation Unit (ACREU) Report. Toronto (ON): University Health Network; 2005 :iv-vi.

6. Petersson I. Evolution of team care and evaluation of effectiveness. Current Opinion Rheumatology. 2005;17:160-163.

7. Widdifield J, Paterson J, Bernatsky S, et al. The rising burden of rheumatoid arthritis surpasses rheumatology supply in Ontario. Canadian Journal of Public Health. 2013;104(7):450-455.

8. Hanly JG. Manpower in Canadian academic rheumatology units: current status and future trends. Canadian Council of Academic Rheumatologists. Journal of Rheumatology. 2001;28(9):1944-1951.

9. Ministry of Health Long Term Care-Ontario (MOHLTC). Making Healthy Change Happen: Ontario's Action Plan for Health Care. Toronto (ON): MOHLTC; 2012. Available from: http://www.health.gov.on.ca/en/ news/speech/2012/sp_20120130.aspx. Retrieved December 14, 2012.
10. Bridges J, Meyer J. Policy on new workforce roles: a discussion paper. International Journal of Nursing Studies. 2007;44(4):635-644.

11. Canadian Medical Association. Arthritis Care in Ontario is Enhanced by Extended-Role Practitioners. Ottawa (ON): Canadian Medical Association; 2011. http://www.facturation.net/learning/arthritis-careontario-enhanced. Accessed June 19, 2015.

12. Kaplan RS, Norton DP. Translating Strategy into Action: The Balanced Scorecard. Boston (MA): Harvard Business Press; 1996.

13. Cott C, Jaglal S, McKillop I, et al. Hospital Report 2005: Rehabilitation. Joint Initiative of the Ontario Hospital Association and the Government of Ontario. Toronto: Hospital Report Research Collaborative, University of Toronto; 2005.

14. Warmington K, Passalent L, Kennedy C, Lundon K, Brooks S, Shupak R. The Early Impact of Advanced Clinician Practitioner in Arthritis Care (ACPAC) program-trained Extended Role Practitioners (ERP) on the Ontario Healthcare System: A System Level Evaluation. A Report. Toronto (ON): The Ministry of Health and Long-Term Care; 2011.

15. Lineker S, Lundon K, Shupak R, Schneider R, MacKay C, Varatharasan N. Arthritis extended-role practitioners: impact on community practice (An exploratory study). Physiotherapy Canada. 2011;63(4):434-442.

16. Lundon K, Kennedy C, Rozmovits C, et al. Evaluation of perceived interprofessional care behaviour amongst stakeholders and emergent advanced clinician graduates of an intensive continuing education development initiative in arthritis care. Journal of Interprofessional Care. 2013;27(5):401-407.

17. Passalent L, Kennedy C, Warmington K, et al. System integration and clinical utilization of the Advanced Clinician Practitioner in Arthritis Care (ACPAC) program-trained Extended Role Practitioners in Ontario: a 2-year System-Level Evaluation. Healthcare Policy. 2013;8(4):56-70.

18. Desmeules F, Roy JS, MacDermid J, Champagne F, Hinse O, Woodhouse L. Advanced practice physiotherapy in patients with musculoskeletal disorders: a systematic review. BMC Musculoskeletal Disorders. 2012;13:107-128.

19. Wynne K. Mandate Letter: Health and Long-Term Care. Toronto (ON): Ministry of Government and Consumer Services; 2014. Available from: https://www.ontario.ca/government/2014-mandate-letter-health-andlong-term-care.

20. Bombardier C, Hawker G, Mosher D. The Impact of Arthritis in Canada: Today and Over the Next 30 Years. Toronto (ON): Arthritis Alliance of Canada; 2011. Available from: http://www.arthritisalliance.ca/en. Retrieved December 14, 2011.

21. Saxon R, Gray M, Oprescu F. Extended roles for allied health professionals: an updated systematic review of the evidence. Journal of Multidisciplinary Healthcare. 2014;7:479-488.

22. Stanhope J, Beaton K, Grimmer-Somers K, Morris J. The role of extended scope physiotherapists in managing patients with inflammatory arthropathies: a systematic review. Open Access Rheumatology: Research and Reviews. 2012;4:49-55.

23. Hospital for Sick Children. Definition of Medical Directives. Toronto $(\mathrm{ON})$ : SickKids. Available from: http://www.sickkids.ca/medicaldirectives/101/definition/index.html. Retrieved December 10, 2012. 
Journal of Multidisciplinary Healthcare

Dovepress

\section{Publish your work in this journal}

The Journal of Multidisciplinary Healthcare is an international, peerreviewed open-access journal that aims to represent and publish research in healthcare areas delivered by practitioners of different disciplines. This includes studies and reviews conducted by multidisciplinary teams as well as research which evaluates the results or conduct of such teams or healthcare processes in general. The journal covers a wide range of areas and welcomes submissions from practitioners at all levels, from all over the world. The manuscript management system is completely online and includes a very quick and fair peer-review system. Visit http://www.dovepress.com/testimonials.php to read real quotes from published authors.

Submit your manuscript here: http://www.dovepress.com/journal-of-multidisciplinary-healthcare-journal 